\title{
A rare cause of acute abdomen: spontanous uterine rupture
}

\author{
Bulent Sultanoglu ${ }^{1 *}$, Kenan Demirbakan $^{1}$, Elif Eygi ${ }^{2}$
}

\begin{abstract}
The uterine rupture during pregnancy is one of the most serious complications, increase morbidity and maternal and fetal mortality. The uterine rupture by percreta placenta is very rare situation. In this article, the case of a 27 year-old, gravida 5, patient which entered by acute abdominal pain, predominant in the hypogastric region were presented. Physical examination showed increasing abdominal pain with hemodynamic compromise.
\end{abstract}

Keywords: Acute, Emergency surgery, Syncope, uterine perforation, pregnancy

\section{Introduction}

Uterine rupture is an uncommon but potentially lifethreatening obstetrical emergency situation for both mother and fetus. It occurs mostly during labor in the context of a previous uterine scar. Generally, uterine rupture refers to a complete separation of all uterine layers, including the uterine serosa, and this usually occurs most commonly in the setting of classical cesarean section (1). The incidence of uterine rupture varies depending on the type and location of the prior uterine incision. The American College of Obstetricians \& Gynecologists (ACOG) Practice Bulletin reports a uterine rupture risk of 0.5 to 0.9 percent for women with prior cesarean undergoing trial of labor (2). However, the overall rate for uterine rupture with previous classical cesarean varies 0.6 to 12 percent as cited in the literature.

\section{Case}

A 27 years old (gravida 5 parity 4) woman applied to emergency service with complaints of syncope and dyspnea, acute abdominal pain and hemorrhagic shock. As to physical examination, she had a Glasgow coma scale of 15 , tension arterial of $80 / 30$ $\mathrm{mmHg}$, pulse rate of 130 beats/minute. There was defence and rebound in all abdomen quadrants. Emergency ultrasound was performed in emergency department. USG revealed free fluid in the abdomen. An emergency laparotomy was performed for a probable diagnosis of intra-abdominal hemorrhage and the fetus found floating freely in the peritoneal cavity (Figure 1). Obstetrical hysterectomy was performed (Figure 2,3), Diagnosis of uterine rupture by percreta placenta were confirmed. The patient recovered and discharged healthy 5 days after the operation, while the fetus could not survive.



Figure 1: Surgery of peritoneal cavity



Figure 2: Obstetrical hysterectomy of Uterine

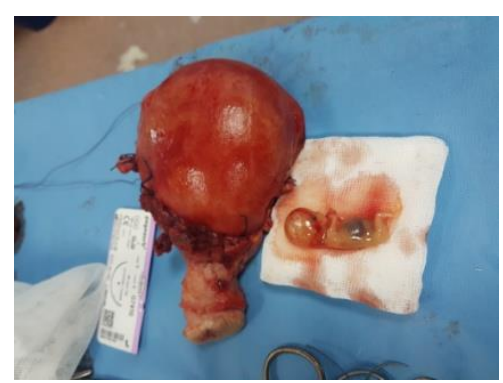

Figure 2: Obstetrical hysterectomy of Uterine

Received 10-11-2017 Accepted 22-11-2017 Available Online 30-12-2017

1 Dr. Ersin Arslan Training and Research Hospital Dept. of General Surgery Department, Gaziantep, TR

2 Dr. Ersin Arslan Training and Research Hospital Dept. of Anesthesiology and Reanimation, Gaziantep, TR

* Corresponding Author: Bulent Sultanoglu E-mail: drbulentsultan@ hotmail.com Phone: +90 3423382525 


\section{Discussion}

Spontaneous uterine rupture due to placenta percreta is a rare obstetric emergency with an estimated incidence of $1 / 5,000$ pregnancies (3). Placenta percreta accounts for $5 \%$ of all placental invasion anomalies (4). Previous Caesarian section is the most common predisposing factor of abnormal placentation. The other risk factors are placenta previa, submucous myoma, endometritis, Asherman's Syndrome, increased maternal age, uterine curettage (5). In our case, the patient had 4 Caesarian operations.

Spontaneous uterine rupture due to placenta percreta is rare. But it can be life threatening for both mother and fetus. The main cause of that in such cases is hemorrhage, disseminated intravascular coagulation and shock. The clinical spectrum of disease varies from abdominal pain to shock. In this case, the patient had hypovolemic shock. Intraabdominal hemorrhage due to placenta percreta could mimic many conditions. The differential diagnosis reveals intraabdominal solid organ rupture (such as hepatic or splenic rupture), ovarian cyst rupture and heterotopic pregnancy.

Antenatal ultrasound is the technique of choice used to establish the diagnosis and guide clinical management as it is cost-effective and popular. If the ultrasound findings are suspicious or the placenta is located on the posterior wall, magnetic resonance imaging can be performed. It provides crucial information on the vascularization of the anatomic planes and of the degree of invasion, modifies the surgical strategy (6). The differential diagnosis constitutes a particular challenge for clinician as massive blood can be life threatening to patient. In our case, ultrasonography performed in emergency department. But the diagnosis was confirmed in the preoperative period.

Placenta percreta can be managed in two ways, first is surgical removal of the uterus and the surrounding tissues and another is conservative therapy including localized resection of the placental implantation site, over sewing, blunt dissection and packing techniques. The choice between hysterectomy and conservative therapy is dependent on the severity of the placenta percreta and associated complications (7). Hysterectomy is considered to be the gold standard approach in a hemodynamically unstable patient with massive intraperitoneal bleeding (8)

\section{Conclusion}

Placenta percreta induced spontaneous uterine rupture is difficult to diagnose. The possibility of uterine rupture should always be kept in mind when a patient admitted to emergency department with complaints of syncope and dyspnea, acute abdominal pain and hemorrhagic shock
Acknowledgments: This case report study was performed at Dr. Ersin Arslan Goverment Hospital, Gaziantep, Turkey

Conflict of Interest: The authors declare no potential conflicts of interest with respect to the research, authorship, and/or publication of this article.

Author's Contributions: B.S.; Writing Editing B.S., K.D. E.E.; Surgery Team.

Ethical issues: All Authors declare that Originality of research/article etc... and ethical approval of research, and responsibilities of research against local ethics commission are under the Authors responsibilities. The study was conducted due to defined rules by the Local Ethics Commission guidelines and audits.

\section{References}

1. Landon MB. Predicting uterine rupture in women undergoing trial of labor after prior cesarean delivery. InSeminars in perinatology 2010 Aug 31 (Vol. 34, No. 4, pp. 267-271). WB Saunders.

2. American College of Obstetricians and Gynecologists. ACOG Practice bulletin no. 115: Vaginal birth after previous cesarean delivery. Obstetrics and gynecology. 2010 Aug;116(2 Pt 1):450..

3. Gardeil F, Daly S, Turner MJ. Uterine rupture in pregnancy reviewed. European Journal of Obstetrics \& Gynecology and Reproductive Biology. 1994 Aug 1;56(2):107-10.

4. Roeters AE, Oudijk MA, Heydanus R, Bruinse HW. Pregnancy outcome after intra-abdominal bleeding due to placenta percreta at 14 weeks of gestation. Obstetrics \& Gynecology. 2007 Feb 1;109(2, Part 2):574-6.

5. Oyelese Y, Smulian JC. Placenta previa, placenta accreta, and vasa previa. Obstetrics \& Gynecology. 2006 Apr 1;107(4):92741 .

6. Marcos HB, Semelka RC, Worawattanakul S. Normal placenta: gadolinium-enhanced dynamic MR imaging. Radiology. 1997 Nov;205(2):493-6.

7. Kazandi M. Placenta percreta: report of two cases and review of the literature. Clinical and experimental obstetrics \& gynecology. 2003;30(1):70-2.

8. Sparić R, Mirković L, Ravilić U, Janjić T. Obstetric complications of placenta previa percreta. Vojnosanitetski pregled. 2014;71(12):1163-6. 